\title{
Methodological Considerations in Social Cost Studies of Addictive Substances: A Systematic Literature Review
}

\begin{abstract}
Nick Verhaeghe ${ }^{1,2 *}$, Delfine Lievens ${ }^{3}$, Lieven Annemans ${ }^{2}$, Freya Vander Laenen ${ }^{3}$ and Koen Putman ${ }^{1}$

'Department of Public Health, Interuniversity Centre for Health Economics Research (I-CHER), Vrije Universiteit Brussel, Brussels, Belgium, ${ }^{2}$ Department of Public Health, Interuniversity Centre for Health Economics Research (I-CHER), Ghent University, Ghent, Belgium, ${ }^{3}$ Institute for International Research on Criminal Policy (IRCP), Ghent University, Ghent, Belgium
\end{abstract}

Background: Alcohol, tobacco, illicit drugs, and psychoactive pharmaceuticals' use is associated with a higher likelihood of developing several diseases and injuries and, as a consequence, considerable health-care expenditures. There is yet a lack of consistent methodologies to estimate the economic impact of addictive substances to society. The aim was to assess the methodological approaches applied in social cost studies estimating the economic impact of alcohol, tobacco, illicit drugs, and psychoactive pharmaceuticals.

Methods: A systematic literature review through the electronic databases, Medline (PubMed) and Web of Science, was performed. Studies in English published from 1997 examining the social costs of the addictive substances alcohol, tobacco, illicit drugs, and psychoactive pharmaceuticals were eligible for inclusion.

Results: Twelve social cost studies met the inclusion criteria. In all studies, the direct and indirect costs were measured, but the intangible costs were seldom taken into account. A wide variety in cost items included across studies was observed. Sensitivity analyses to address the uncertainty around certain cost estimates were conducted in eight studies considered in the review.

Conclusion: Differences in cost items included in cost-of-illness studies limit the comparison across studies. It is clear that it is difficult to deal with all consequences of substance use in cost-of-illness studies. Future social cost studies should be based on sound methodological principles in order to result in more reliable cost estimates of the economic burden of substance use.

Keywords: cost-of-illness, methodology, review, alcohol, tobacco, illicit drugs, psychoactive pharmaceuticals

\section{INTRODUCTION}

The use and/or misuse of the addictive substances alcohol, tobacco, and illicit drugs are a worldwide problem contributing to the global burden of disease (1). Alcohol is responsible for 3.3 million deaths (5.9\% of all deaths worldwide) each year and accounts for $5.1 \%$ of the global burden of disease (2). In 2015, tobacco smoking including second-hand smoking accounted for 7.2 million deaths (1), while for illicit drugs, this was $0.8 \%$ (3). In addition, the misuse of psychoactive pharmaceuticals such 
as antidepressants, sedatives, anxiolytics, and antipsychotics has also become a public health concern (4). The scale of the impact of the misuse of such pharmaceuticals worldwide remains, however, unknown due to a lack of epidemiological data. Nevertheless, a high prevalence of non-medical prescription drug use has been reported in countries such as the US, Canada, Australia, and some European countries $(5,6)$.

The use of alcohol, tobacco, illicit drugs, and psychoactive pharmaceuticals is associated with a considerable risk of developing a number of diseases and injuries $(7,8)$. So, it is clear that they affect the health and economic welfare of societies. The economic burden of these addictive substances can be estimated by costof-illness studies (9). In such studies, the social costs associated with a particular disease or condition are measured by estimating the direct, the indirect, and the intangible costs. The direct costs are those to deal with the disease, or condition, or its proximate effects (e.g., hospitalization and medication). The indirect costs are the costs related to lost human productivity (e.g., productivity losses due to morbidity or mortality). The intangible costs can be considered as non-financial welfare losses such as reduced health-related quality of life $(9,10)$.

In general, two approaches are used in cost-of-illness studies, namely, the prevalence-based and the incidence-based approaches. Prevalence-based studies estimate the costs associated with past and current consequences of the disease or condition in a given time period, typically a year. The incidence-based approach estimates the costs and consequences associated with new cases of the disease or condition in the current and future years (8). The indirect costs can be measured using the human capital method, the demographic method, and the friction cost method. The human capital method measures the current and future productivity losses occurring in the current year $(10,11)$. The demographic method measures the current costs from all current and past productivity losses by comparing the current population with a hypothetical population in which the disease or condition did not exist $(10,11)$. The friction cost method takes into account the productivity losses related to the time period until another employee takes over the work at the same capacity (12). The epidemiological concept of substance-attributable fractions (SAF) can be used to quantify the proportion of morbidity and mortality of diseases and conditions known to be causally related to substance use $(13,14)$.

Comparing the findings of social cost studies is difficult and must be cautiously interpreted due to differences in methodologies such as cost items included or calculation methods (15). Social cost studies are frequently characterized by some degree of uncertainty related to the availability and reliability of data sources (10). With the current review, it was the aim to evaluate the methodological approaches applied in social cost studies of the addictive substances alcohol, tobacco, illicit drugs, and psychoactive pharmaceuticals.

\section{METHODS}

A systematic literature search was conducted searching the electronic peer-reviewed databases, Medline (PubMed) and Web of Science. For each of the databases, a search algorithm was developed adapted to the specific requirements or features of the databases using the following entry terms: "cost-of-illness" (MeSH), "health-care costs" (MeSH), "cost," "costs," "social," "societal," "direct," "indirect," "intangible," "alcohol," "tobacco" (MeSH), "illicit," "illegal," and "psychotropic drugs" (MeSH). The initial search yielded 1,173 records. After excluding the duplicates ( $n=15), 1,158$ records remained for further evaluation (Figure 1). First, a selection on title and/or abstract was performed. Studies in English conducted in high-income Western countries estimating the social costs of the substances alcohol, tobacco, illicit drugs, and psychoactive pharmaceuticals were eligible for inclusion. In 1996, the first edition of the guidelines for estimating the costs of substance abuse was published (16). Therefore, for this review, studies published from January 1997 until December 2015 were considered. Studies were excluded if they consisted of health economic evaluations of substance abuse treatment or prevention programs, or if the geography, language, and time period criteria were different from those described under the inclusion criteria. The selection on title and/or abstract resulted in 19 records of which the full text was evaluated in detail on the inclusion and exclusion criteria. Seven records were excluded resulting in 12 social cost studies included in the review. The outcomes of interest included the substance under study, the cost measurement approach (incidence-based or prevalence-based), the major cost categories considered (direct, indirect, and intangible costs),

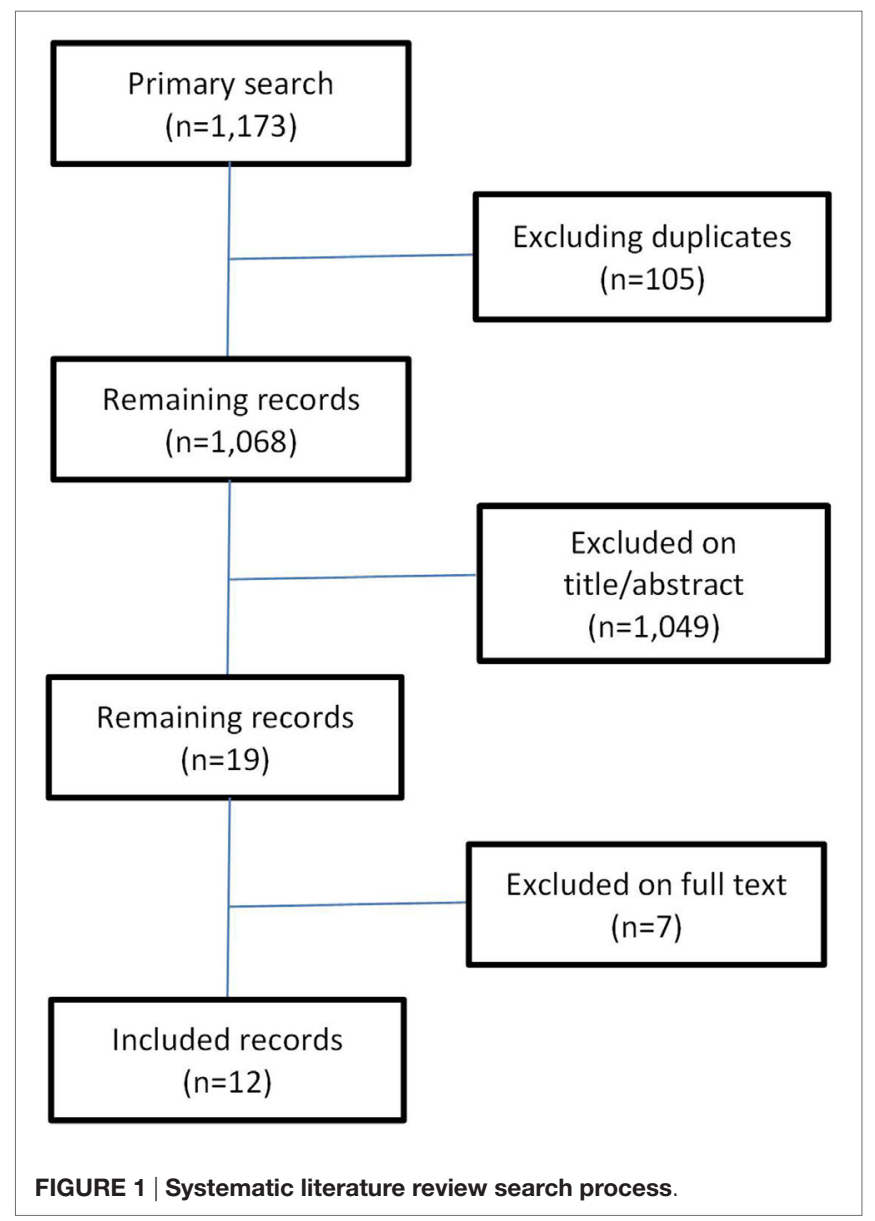


productivity losses measurement (human capital, demographic, or friction cost measurement), cost items considered, and a number of reporting issues. Study quality was assessed using a checklist for social cost studies (Table A1 in Appendix) (17).

\section{RESULTS}

The literature review encompassed 12 studies. Five of them were conducted in Germany (18-22), while the remaining were from Canada (23), Denmark (24), France (25), Scotland (26), Spain (27), Sweden (28), and the US (29). In two studies $(23,25)$, the social costs of alcohol, tobacco, and illicit drugs were estimated, while in the other studies, the economic impact of one particular substance was considered (Table 1). A prevalence-based approach was used in 11 of 12 studies (Table 1). In all studies, both the indirect and the direct cost categories were accounted for, while in only two studies $(19,28)$, also welfare losses were considered. In Jarl et al. (28), quality of life of alcohol consumers, their family, and friends was taken into account by calculating the number of quality-adjusted life years (QALYs) for the consumers and a weighted quality of life estimate for the relatives. In Konnopka and König (19), also QALYs were used to express the impact of alcohol on quality of life of individuals consuming moderate alcohol levels. In both studies in the base case analysis, no monetary valuation of the alcohol-attributable welfare losses was included. The human capital approach was used in all studies to estimate the indirect costs associated with substance use (Table 1).

Information on the total costs as a proportion of the gross domestic product (GDP) was provided in four studies (Table 2). The quantification of the amount of morbidity and mortality that could be attributed to legal or illegal drugs occurred in seven studies by applying the concept of SAFs (Table 2). In all seven studies, information on the input parameters to calculate the SAFs was provided. In the study by Ruff et al. (21), attributable risks for tobacco-associated diseases were applied, but no information on the data source was provided. In Garcia-Altes et al. (27), the estimation of the attributable risks was based on the findings from previous studies and on Spanish statistical data. Sensitivity analyses were conducted in eight studies (Table 2). In general, three categories of sensitivity analyses could be distinguished (Table 3). A first category was related to the use of alternative methodological approaches. In five studies $(18,20,22,23,28)$, this consisted of applying the friction cost method as an alternative method to estimate the substance-attributable indirect costs. In one study (28), as a sensitivity analysis, the welfare losses-expressed as QALYs-were valued. A second category included sensitivity analyses related to the inclusion or exclusion of certain cost items (Table 3). In a third category of sensitivity analyses, input parameters such as the relative risks of the substance-attributable diseases or resource use were varied (Table 3).

In 11 of 12 studies, the major cost categories "direct costs" and "indirect costs" were reported in a disaggregated form (Table 2). This means that, for each cost item, detailed information on the costs was provided. Contrary, in the study by Rasmussen et al. (24), only the total direct and indirect tobacco-attributable costs were reported. For the direct costs, substance-attributable hospitalization costs were included in all studies, followed by pharmaceuticals $(n=11)$, and primary care costs $(n=9)$. Contrary, a number of cost items such as accident and emergency care, laboratory tests, home-based nursing care, and household care were accounted for in only a limited number of studies (Table 4). An important reason for not considering certain cost items was the absence of accurate and reliable data. For the indirect costs, disability/absenteeism and premature mortality were accounted for in 11 studies each, while substance-attributable costs related to unemployment were included in only two studies (Table 4).

As an example to illustrate how differences in cost items included may have affected the cost outcomes, we focus on the five studies conducted in Germany (18-22). For these studies, a more in-depth analysis of differences in cost items considered was performed. Certain cost items such as hospitalization, rehabilitation, and medication use were included in all five studies. Others were only considered in one particular study such as substance-attributable costs for home-based nursing care (21), household care (19), or non-medical costs (18) (Table 4). For the indirect costs, expenditures associated with disability, premature mortality, and early retirement were accounted for in four of five studies (18-21). In the study by Wacker et al. (22), only indirect costs due to disability were included in the analysis.

TABLE 1 | Overview of social cost studies included in the literature review.

\begin{tabular}{|c|c|c|c|c|c|}
\hline Reference & Country & Substance & Cost categories & Cost measurement & $\begin{array}{l}\text { Productivity losses } \\
\text { measurement }\end{array}$ \\
\hline Ruff et al. (21) & Germany & Tobacco & Direct costs/indirect costs & Prevalence-based & Human capital method \\
\hline Garcia-Altes et al. (27) & Spain & Illicit drugs & Direct costs/indirect costs & Prevalence-based & Human capital method \\
\hline Varney and Guest (26) & Scotland & Alcohol & Direct costs/indirect costs & Prevalence-based & Human capital method \\
\hline Fenoglio et al. (25) & France & Alcohol, tobacco, and illicit drugs & Direct costs/indirect costs & Prevalence-based & Human capital method \\
\hline Rasmussen et al. (24) & Denmark & Tobacco & Direct costs/indirect costs & Incidence-based & Human capital method \\
\hline Neubauer et al. (20) & Germany & Tobacco & Direct costs/indirect costs & Prevalence-based & Human capital method \\
\hline Konnopka and König (18) & Germany & Alcohol & Direct costs/indirect costs & Prevalence-based & Human capital method \\
\hline Rehm et al. (23) & Canada & Alcohol, tobacco, and illicit drugs & Direct costs/indirect costs & Prevalence-based & Human capital method \\
\hline Jarl et al. (28) & Sweden & Alcohol & $\begin{array}{l}\text { Direct costs/indirect costs/intangible } \\
\text { costs }\end{array}$ & Prevalence-based & Human capital method \\
\hline Konnopka et al. (33) & Germany & Alcohol & $\begin{array}{l}\text { Direct costs/indirect costs/intangible } \\
\text { costs }\end{array}$ & Prevalence-based & Human capital method \\
\hline Hansen et al. (29) & US & Psychoactive pharmaceuticals & Direct costs/indirect costs & Prevalence-based & Human capital method \\
\hline Wacker et al. (22) & Germany & Tobacco & Direct costs/indirect costs & Prevalence-based & Human capital method \\
\hline
\end{tabular}


TABLE 2 | Reporting issues of the studies included in the review.

\begin{tabular}{|c|c|c|c|c|c|}
\hline Reference & Substance & Details on cost items & Sensitivity analyses & $\%$ of GDP & SAF \\
\hline Ruff et al. (21) & Tobacco & Disaggregated & No & No & Not clear \\
\hline Garcia-Altes et al. (27) & Illicit drugs & Disaggregated & No & Yes & No \\
\hline Varney and Guest (26) & Alcohol & Disaggregated & Yes & No & No \\
\hline Fenoglio et al. (25) & Alcohol/tobacco/illicit drugs & Disaggregated & No & Yes & Yes \\
\hline Rasmussen et al. (24) & Tobacco & Aggregated & Yes & No & Yes \\
\hline Neubauer et al. (20) & Tobacco & Disaggregated & Yes & No & Yes \\
\hline Konnopka and König (18) & Alcohol & Disaggregated & Yes & Yes & Yes \\
\hline Rehm et al. (23) & Alcohol/tobacco/illicit drugs & Disaggregated & Yes & No & Yes \\
\hline Jarl et al. (28) & Alcohol & Disaggregated & Yes & Yes & Yes \\
\hline Konnopka et al. (33) & Alcohol & Disaggregated & Yes & No & Yes \\
\hline Hansen et al. (29) & Psychoactive pharmaceuticals & Disaggregated & No & No & No \\
\hline Wacker et al. (22) & Tobacco & Disaggregated & Yes & No & No \\
\hline
\end{tabular}

SAF, substance-attributable fraction; GDP, gross domestic product.

TABLE 3 | Applied sensitivity analyses in the studies included in the review.

\begin{tabular}{|c|c|c|}
\hline Category & Type & Reference \\
\hline \multirow[t]{2}{*}{$\begin{array}{l}\text { Methodological } \\
\text { approaches }\end{array}$} & Friction cost method & $\begin{array}{l}\text { Wacker et al. (22), Jarl et al. (28), } \\
\text { Konnopka and König (18), Rehm } \\
\text { et al. (23), and Neubauer et al. (20) }\end{array}$ \\
\hline & Valuation of QALYS & Jarl et al. (28) \\
\hline \multirow[t]{2}{*}{ Cost items } & $\begin{array}{l}\text { Exclusion of unpaid } \\
\text { work }\end{array}$ & $\begin{array}{l}\text { Konnopka et al. (33), Konnopka and } \\
\text { König (18) }\end{array}$ \\
\hline & $\begin{array}{l}\text { Inclusion of unpaid } \\
\text { work }\end{array}$ & Neubauer et al. (20) \\
\hline \multirow[t]{4}{*}{ Input parameters } & Resource use & $\begin{array}{l}\text { Wacker et al. (22), Jarl et al. (28), and } \\
\text { Varney and Guest (26) }\end{array}$ \\
\hline & Relative risks & $\begin{array}{l}\text { Konnopka et al. (33) and Rasmussen } \\
\text { et al. (24) }\end{array}$ \\
\hline & $\begin{array}{l}\text { Substance } \\
\text { consumption rates }\end{array}$ & Konnopka et al. (33) \\
\hline & Discount rates & $\begin{array}{l}\text { Konnopka et al. (33), Konnopka and } \\
\text { König (18), and Rasmussen et al. (24) }\end{array}$ \\
\hline
\end{tabular}

QALYS, quality-adjusted life years.

\section{DISCUSSION}

The aim of the current literature review was to evaluate the methodological approaches and considerations in studies examining the economic impact of alcohol, tobacco, illicit drugs, and psychoactive pharmaceuticals. In 11 of 12 studies included in the review, the prevalence-based approach was used. The choice for a prevalence-based or an incidence-based method is depending on the aim of the study. A prevalence-based approach is more appropriate for estimating the economic burden of a substance in a specified time period. The incidence-based approach portrays the magnitude of the economic impact during an individuals' life course, thus providing insights into the value of preventing a case of substance use (8). In all studies, the major cost categories such as direct costs and indirect costs were included, while the intangible costs were accounted for in only two studies. The latter costs are often ignored in social cost studies of substance misuse since it is difficult to place a monetary value upon welfare losses (30). Considerable differences were found related to the cost items included or excluded across the studies in the review. Our findings are similar with those of a previous literature review, however, limited to social cost studies examining the economic burden of alcohol. Differences in methodologies related to the availability and accuracy of data were found to be important reasons explaining the differences in cost estimates (31). Our review was extended to all addictive substances. We found not only differences in method but also differences in the drug under study, with only limited studies examining more than one substance. It is clear that methodological inconsistencies have important effects putting the reliability of cost-of-illness findings into question. This may result in an underestimation or overestimation of the real economic burden of substance misuse to society (32). This is a critical element since the findings of such studies may serve as the basis for comparative health economic evaluations or for policy decisions (8). Methodological considerations are not limited to cost-of-illness studies of substance use, but they were also found in several literature reviews of the economic impact of mental disorders (33-35). For example, in their review, Luppa et al. (34) found that costs of morbidity and mortality were included in only half and in one-third of studies examining the social costs of depression.

It is thus clear that comparing the findings of social cost studies is difficult. A possible basis for comparing the findings across studies is presenting them relative to a country's GDP. This occurred in four studies included in the current review. Nevertheless, even if a uniform methodology was to be developed and used, cross-country comparisons would necessitate sufficient contextualization since countries differ in terms of social security systems, institutional structures, and cultural traditions (36). In 11 of 12 studies included in the review, information on the relative proportion of the different cost items to the total costs was provided. This is important because different stakeholders may be interested in different outcomes. For governments, the findings can assist them in their decisions related to the funding of interventions designed to reduce the burden of substance misuse. Information regarding the impact of substance misuse on productivity can be useful for employers, while for households, the impact on medical or other expenses can be relevant $(15,16)$. Sensitivity analyses were applied in eight studies included in the review. Uncertainty around certain cost estimates in cost-of-illness studies is almost self-evident. It is, however, necessary to address this and inform the reader about 
TABLE 4 | Cost items pertaining to the major cost categories included in the social cost studies.

\begin{tabular}{|c|c|c|c|c|c|c|c|c|c|c|c|c|}
\hline Cost items & $\begin{array}{l}\text { Ruff } \\
\text { et al. } \\
(21)\end{array}$ & $\begin{array}{c}\text { Garcia- } \\
\text { Altes } \\
\text { et al. } \\
\text { (27) }\end{array}$ & $\begin{array}{c}\text { Varney } \\
\text { and } \\
\text { Guest } \\
\text { (26) }\end{array}$ & $\begin{array}{l}\text { Fenoglio } \\
\text { et al. (25) }\end{array}$ & $\begin{array}{c}\text { Rasmussen } \\
\text { et al. (24) }\end{array}$ & $\begin{array}{l}\text { Neubauer } \\
\text { et al. (20) }\end{array}$ & $\begin{array}{c}\text { Konnopka } \\
\text { and König } \\
\text { (18) }\end{array}$ & $\begin{array}{c}\text { Rehm } \\
\text { et al. } \\
\text { (23) }\end{array}$ & $\begin{array}{c}\text { Jarl } \\
\text { et al. } \\
(28)\end{array}$ & $\begin{array}{c}\text { Konnopka } \\
\text { et al. (33) }\end{array}$ & $\begin{array}{c}\text { Hansen } \\
\text { et al. } \\
\text { (29) }\end{array}$ & $\begin{array}{c}\text { Wacker } \\
\text { et al. } \\
\text { (22) }\end{array}$ \\
\hline \multicolumn{13}{|l|}{ Direct costs } \\
\hline Hospitalization & $x$ & $x$ & $x$ & $x$ & $x$ & $x$ & $x$ & $x$ & $x$ & $x$ & $x$ & $x$ \\
\hline$A \& E$ & & $x$ & $x$ & & & & & & & & & \\
\hline Ambulatory care & $x$ & & $x$ & & $x$ & $x$ & $x$ & $x$ & & & $x$ & $x$ \\
\hline Ambulance & & $x$ & $x$ & $x$ & & & & & & & & \\
\hline Residential care & & & & $x$ & & & & $x$ & & $x$ & & \\
\hline Rehabilitation & $x$ & & & & & $x$ & $x$ & & & $x$ & & $x$ \\
\hline Pharmaceuticals & $x$ & $x$ & $x$ & $x$ & $x$ & $x$ & $x$ & $x$ & $x$ & $x$ & & $x$ \\
\hline Primary care & & $x$ & $x$ & $x$ & $x$ & $x$ & & & $x$ & $x$ & $x$ & $x$ \\
\hline Laboratory tests & & & $x$ & & & & & & & & & \\
\hline Home-based nursing care & $x$ & $x$ & & & & & & & & & & \\
\hline Social services & & & $x$ & & & & & & $x$ & & & \\
\hline Household care & & & & & & & & & & $x$ & & \\
\hline Non-medical costs & & & & & & & $x$ & & & & & \\
\hline Education & & $x$ & & & & & & & & $x$ & & \\
\hline Prevention & & $x$ & $x$ & $x$ & & & & $x$ & $x$ & $x$ & & \\
\hline Research & & $x$ & & $x$ & & & & $x$ & $x$ & $x$ & & \\
\hline \multicolumn{13}{|l|}{ Indirect costs } \\
\hline Disability/absenteeism & $x$ & $x$ & $x$ & $x$ & $x$ & $x$ & $x$ & $x$ & $x$ & $x$ & & $x$ \\
\hline Unemployment & & & $x$ & & & & & & & & $x$ & \\
\hline Premature mortality & $x$ & $x$ & $x$ & $x$ & $x$ & $x$ & $x$ & $x$ & $x$ & $x$ & $x$ & \\
\hline Early retirement & $x$ & & & & $x$ & $x$ & $x$ & & $x$ & $x$ & & \\
\hline \multicolumn{13}{|l|}{ Intangible costs } \\
\hline QALY & & & & & & & & & $x$ & $x$ & & \\
\hline
\end{tabular}

A\&E, Accident and Emergency Department; QALY, quality-adjusted life year.

the amount of uncertainty associated with the cost estimate outcomes (10).

Some limitations of our review need to be addressed. First, no robust analysis of the magnitude of the economic impact in monetary terms was performed, since we focused on methodological issues of social cost studies of substance use. Nevertheless, as an example, the influence of methodological choices on the cost outcomes for the German studies was examined. Second, in a number of studies (25-29), also drug-attributable crime and law enforcement costs were estimated. For the current review, methodological considerations related to the estimation of these costs were not considered. It is yet important to not omit these costs in studies examining the economic impact of substance use, since they may account for a considerable part of the total costs $(23,37,38)$. For example, in the study by Rehm et al. (23) examining the social costs of alcohol, tobacco, and illicit drugs, the costs for law enforcement constituted more than one-third of the direct costs. Third, only studies published after the introduction of the guidelines for estimating the costs of substance abuse in 1996 were eligible for inclusion in the review. It is thus possible that we missed some relevant studies prior to 1997. Fourth, we did not search the gray literature. It is thus possible that we have missed social cost studies of addictive substances not published in peer-reviewed journals. Fifth, the current review was limited to social cost studies conducted in high-income countries. However, the economic burden attributable to the addictive substances alcohol, tobacco, and illicit drugs is also considerable in lowand middle-income countries (39). So, it is clear that addictive substances pose a considerable economic impact to societies worldwide. In conclusion, the current review has illustrated the complexity of dealing with all consequences of substance use in cost-of-illness studies. Future social cost studies should be based on sound methodological principles in order to result in more reliable cost estimates of the economic burden of substance use. This is important since the findings of such studies may be used as the basis for comparative health economic evaluations and for substance use policies.

\section{AUTHOR CONTRIBUTIONS}

NV contributed to the development of the study, conducted the literature search, and drafted the manuscript. KP participated in the development of the methods and reviewed the manuscript. LA, DL, and FL revised the manuscript. All the authors approved the final version of the manuscript.

\section{FUNDING}

The study was funded by the Federal Public Planning Service Science Policy (BELSPO-DR/00/065). 


\section{REFERENCES}

1. GBD 2015 Risk Factors Collaborators. Global, regional, and national comparative risk assessment of 79 behavioural, environmental and occupational, and metabolic risks or cluster of risks, 1990-2015: a systematic analysis for the Global Burden of Disease Study 2015. Lancet (2016) 388:1659-724. doi:10.1016/S0140-6736(16)31679-8

2. World Health Organization. Global Status Report on Alcohol and Health 2014. Geneva: World Health Organization (2014).

3. Degenhardt L, Whiteford HA, Ferrari AJ, Baxter AJ, Charlson FJ, Hall WD, et al. Global burden of disease attributable to illicit drug use and dependence: findings from the Global Burden of Disease Study 2010. Lancet (2013) 382(9904):1564-74. doi:10.1016/S0140-6736(13)61530-5

4. United Nations Office on Drugs and Crime. World Drug Report 2010. Vienna, Austria: United Nations Office on Drugs and Crime (UNODC) (2010).

5. Jakovljevic MM, Lazarevic M, Jurisevic M, Jovanovic MR. When cure becomes an illness-abuse of addictive prescription medicines. Front Pharmacol (2015) 6:193. doi:10.3389/fphar.2015.00193

6. United Nations Office on Drugs and Crime. World Drug Report 2011. Vienna, Austria: United Nations Office on Drugs and Crime (UNODC) (2011).

7. Fischer B, Bibby M, Bouchard M. The global diversion of pharmaceutical drugsnon-medical use and diversion of psychotropic prescription drugs in North America: a review of sourcing routes and control measures. Addiction (2010) 105(12):2062-70. doi:10.1111/j.1360-0443.2010.03092.x

8. Single E, Collins D, Easton B, Harwood H, Lapsley H, Kopp P, et al. International Guidelines for Estimating the Costs of Substance Abuse. 2nd ed. Geneva: World Health Organization (2003).

9. Rice DP. Cost of illness studies: what is good about them? Inj Prev (2000) 6:177-9. doi:10.1136/ip.6.3.177

10. Moore TJ, Caulkins JP. How cost-of-illness studies can be made more useful for illicit drug policy analysis. Appl Health Econ Health Policy (2006) 5(2):75-85. doi:10.2165/00148365-200605020-00002

11. Cartwright WS. Economic costs of drug abuse: financial, cost of illness, and services. J Subst Abuse Treat (2008) 34(2):224-33. doi:10.1016/j.jsat. 2007.04.003

12. Koopmanschap MA, Rutten FF. The consequence of production loss or increased costs of production. Med Care (1996) 34(12 Suppl):DS59-68.

13. Jones L, Bellis M, Dedman D, Sumnall H, Tocque K. Alcohol-Attributable Fractions for England. Alcohol-Attributable Mortality and Hospital Admissions. Liverpool: Centre for Public Health, Liverpool John Moores University (2008).

14. Kleinbaum D, Kupper L, Morgenstern H. Epidemiologic Research, Principles and Quantitative Methods. New York: Van Nostrand Reinhold (1982).

15. World Health Organization. WHO Guide to Identifying the Economic Consequences of Disease and Injury. Geneva: World Health Organization (2009).

16. Single E, Collins D, Harwood H, Lapsley H, Maynard A. International Guidelines on Estimating the Costs of Substance Abuse. 1st ed. Ottawa: Canadian Centre on Substance Abuse (1996).

17. Drummond M, Sculpher M, Torrance G, O'Brien B, Stoddart G. Methods for the Economic Evaluation of Health Care Programmes. 3rd ed. Oxford: Oxford University Press (2005).

18. Konnopka A, König HH. Direct and indirect costs attributable to alcohol consumption in Germany. Pharmacoeconomics (2007) 25(7):605-18. doi:10.2165/00019053-200725070-00006

19. Konnopka A, König HH. The health and economic consequences of moderate alcohol consumption in Germany 2002. Value Health (2009) 12(2):253-61. doi:10.1111/j.1524-4733.2008.00444.x

20. Neubauer S, Welte R, Beiche A, Koenig HH, Buesch K, Leidl R. Mortality, morbidity and costs attributable to smoking in Germany: update and a 10-year comparison. Tob Control (2006) 15(6):464-71. doi:10.1136/tc.2006. 016030

21. Ruff LK, Volmer T, Nowak D, Meyer A. The economic impact of smoking in Germany. Eur Respir J (2000) 16(3):385-90. doi:10.1034/j.1399-3003.2000. 016003385.x

22. Wacker $M$, Holle $R$, Heinrich J, Ladwig KH, Peters A, Leidl R, et al. The association of smoking status with healthcare utilisation, productivity loss and resulting costs: results from the population-based KORA F4 study. BMC Health Serv Res (2013) 13:278. doi:10.1186/1472-696313-278

23. Rehm J, Gnam W, Popova S, Baliunas D, Brochu S, Fischer B, et al. The costs of alcohol, illegal drugs, and tobacco in Canada, 2002. J Stud Alcohol Drugs (2007) 68(6):886-95. doi:10.15288/jsad.2007.68.886

24. Rasmussen SR, Prescott E, Sorensen TI, Sogaard J. The total lifetime costs of smoking. Eur J Public Health (2004) 14(1):95-100. doi:10.1093/eurpub/ 14.1 .95

25. Fenoglio P, Parel V, Kopp P. The social cost of alcohol, tobacco and illicit drugs in France, 1997. Eur Addict Res (2003) 9(1):18-28. doi:10.1159/000067730

26. Varney SJ, Guest JF. The annual societal cost of alcohol misuse in Scotland. Pharmacoeconomics (2002) 20(13):891-907. doi:10.2165/00019053200220130-00003

27. Garcia-Altes A, Olle JM, Antonanzas F, Colom J. The social cost of illegal drug consumption in Spain. Addiction (2002) 97(9):1145-53. doi:10.1046/ j.1360-0443.2002.00170.x

28. Jarl J, Johansson P, Eriksson A, Eriksson M, Gerdtham UG, Hemstrom O, et al. The societal cost of alcohol consumption: an estimation of the economic and human cost including health effects in Sweden, 2002. Eur J Health Econ (2008) 9(4):351-60. doi:10.1007/s10198-007-0082-1

29. Hansen RN, Oster G, Edelsberg J, Woody GE, Sullivan SD. Economic costs of non-medical use of prescription opioids. Clin J Pain (2011) 27(3):194-202. doi:10.1097/AJP.0b013e3181ff04ca

30. Single E. Estimating the costs of substance abuse: implications to the estimation of the costs and benefits of gambling. J Gambl Stud (2003) 19(2):215-33. doi:10.1023/A:1023633432745

31. Thavorncharoensap M, Teerawattananon Y, Yothasamut J, Lertpitakpong C, Chaikledkaew U. The economic impact of alcohol consumption: a systematic review. Subst Abuse Treat Prev Policy (2009) 4:20. doi:10.1186/1747597X-4-20

32. Jarl J. Cost-of-illness studies on substance use - both under- and overestimated. Nord Stud Alcohol Drugs (2010) 27:339-45.

33. Konnopka A, Leichsenring F, Leibing E, König HH. Cost-of-illness studies and cost-effectiveness analyses in anxiety disorders: a systematic review. J Affect Disord (2009) 114:14-31. doi:10.1016/j.jad.2008.07.014

34. Luppa M, Heinrich S, Angermeyer MC, König HH, Riedel-Heller SG. Costof-illness studies of depression: a systematic review. J Affect Disord (2007) 98(1-2):29-43. doi:10.1016/j.jad.2006.07.017

35. Stuhldreher N, Konnopka A, Wild B, Herzog W, Zipfel S, Löwe B, et al. Cost-of-illness studies and cost-effectiveness analyses in eating disorders: a systematic review. Int J Eat Disord (2012) 45:476-91. doi:10.1002/eat.20977

36. Jakovljevic MM, Potapchik E, Popovich L, Barik D, Getzen TE. Evolving health expenditure landscape of the BRICS Nations and Projections to 2025. Health Econ (2016). doi:10.1002/hec.3406

37. Jakovljevic MM, Jovanovic MR, Nikic K, Radovanovic A, Pirkovic I, Djukic Dejanovic S, et al. Acute alcohol detoxification costs in upper-middle income: Western Balkans. Health Behav Public Health (2011) 1:1-7.

38. Jovanovic MR, Jakovljevic MM. Inpatient detoxification procedure and facilities: financing considerations from an Eastern European perspective. Alcohol Alcohol (2011) 46:364-5. doi:10.1093/alcalc/agr010

39. Rehm J, Taylor B, Room R. Global burden of disease from alcohol, illicit drugs and tobacco. Drug Alcohol Rev (2006) 25:503-13. doi:10.1080/ 09595230600944453

Conflict of Interest Statement: The authors declare that the research was conducted in the absence of any commercial or financial relationships that could be construed as a potential conflict of interest.

Copyright (C) 2017 Verhaeghe, Lievens, Annemans, Vander Laenen and Putman. This is an open-access article distributed under the terms of the Creative Commons Attribution License (CC BY). The use, distribution or reproduction in other forums is permitted, provided the original author(s) or licensor are credited and that the original publication in this journal is cited, in accordance with accepted academic practice. No use, distribution or reproduction is permitted which does not comply with these terms. 


\section{APPENDIX}

TABLE A1 | Quality appraisal of studies included in the literature review.

Quality check item Ruff Garcia-Altes

(21) et al. (27)

Varney and

Fenoglio

Rasmussen

Neubauer Konnopk

Rehm Jarl Konnopka Hansen Wacker Guest (26) et al. (25) et al. (24) et al. (20)

and König

et al.

$\begin{array}{cc}\text { Jarl } & \text { Konnopka } \\ \text { et al. } & \text { et al. (33) }\end{array}$

Hansen
et al. (29)

et al.

Clear definition of the illness?

Epidemiological sources carefully described?

Costs sufficiently disaggregated?

Activity data sources carefully described?

Activity data appropriately assessed?

Sources of all cost values analytically described?

Methods carefully explained?

Costs discounted?

Major assumptions tested in a sensitivity analysis?

Presentation of results consistent with methodology?

\begin{tabular}{|c|c|c|c|c|c|c|c|c|c|c|c|}
\hline$x$ & $x$ & $x$ & $x$ & $x$ & $x$ & $x$ & $x$ & $x$ & $x$ & $x$ & $x$ \\
\hline$x$ & $x$ & $x$ & $x$ & $x$ & $x$ & $x$ & $x$ & $x$ & $x$ & $x$ & $x$ \\
\hline$x$ & $x$ & $x$ & $x$ & & $x$ & $x$ & $x$ & $x$ & $x$ & $x$ & $x$ \\
\hline \multirow[t]{4}{*}{$x$} & $x$ & $x$ & $x$ & $x$ & $x$ & $x$ & $x$ & $x$ & $x$ & $x$ & $x$ \\
\hline & & $x$ & & & & $x$ & & & $x$ & & $x$ \\
\hline & $x$ & $x$ & $x$ & $x$ & $x$ & $x$ & $x$ & $x$ & $x$ & $x$ & $x$ \\
\hline & $x$ & $x$ & $x$ & & $x$ & $x$ & $x$ & $x$ & $x$ & $x$ & \\
\hline \multirow[t]{2}{*}{$x$} & & & & & $x$ & $x$ & $x$ & $x$ & $x$ & & $x$ \\
\hline & & $x$ & & $x$ & $x$ & $x$ & $x$ & $x$ & $x$ & & $x$ \\
\hline$x$ & $x$ & $x$ & $x$ & $x$ & $x$ & $x$ & $x$ & $x$ & $x$ & $x$ & $x$ \\
\hline
\end{tabular}

